\title{
Poesía y Pintura. Frank O'Hara y el expresinionismo abstracto
}

\section{Poetry and painting. Frank O'hara and abstract expressionism}

\author{
Alberto Santamaría \\ Universidad de Salamanca. España. \\ albertosantamaria@usal.es
}

\section{Resumen}

El objetivo de este artículo es analizar las relaciones entre poesía y pintura en el seno del expresionismo abstracto. Para ello tomamos tres nombres de referencia: Clement Greenberg (crítico de arte), Frank O'Hara (poeta) y Willem De Kooning (pintor). A través de estos nombres tratamos de señalar la estrecha relación que existía entre poetas y pintores en la llamada Escuela de Nueva York.

Palabras clave: Pintura, poesía, expresionismo abstracto, O'Hara, De Kooning.

\section{Abstract}

The aim of this article is to analyze the relationship between poetry and painting in the Abstract Expressionism. For that three names: Clement Greenberg (art critic), Frank O'Hara (a poet) and Willem De Kooning (painter). Through these names try to point out the close relationship between poets and painters in the so-called New York School.

Keywords: Painting, Poetry, Abstract Expressionism, O'Hara, De Kooning. 


\section{El caso T. S. Eliot como preludio}

A los pocos días de estallar la II Guerra Mundial Clement Greenberg publica en Partisan Review su conocido texto "Vanguardia y Kitsch". Con este texto Greenberg trataba de dar respuesta a una obsesión común en buena parte de los intelectuales de esa década de 1930. Esto es, la necesidad de analizar un fenómeno como era la vanguardia (con su particular e intraducible lenguaje) en conexión con otro fenómeno propio del cambio de siglo: la cultura de masas. Todo ello desde una perspectiva donde la política jugaba un papel capital, como garante de la supervivencia de esa vanguardia. Un tema que, desde ángulos sutilmente diferentes, ya antes había sido objeto de estudio por parte de Walter Benjamin ("La obra de arte en la época de su reproductibilidad técnica") y más tarde lo será por Adorno y Horckheimer en "La industria cultural".

Sin embargo, lo que más me interesa de ese texto ahora no son estas conexiones -centrales, por supuesto, para entender el arte del siglo XX-. Ni siquiera son esas temáticas en torno a las políticas culturales, sino que mi interés se situará en torno a algo que permanece y aparece, digamos, velado, en una lectura entrelíneas. Este texto, considerado el primer texto importante en su trayectoria como crítico de arte, contiene la sorpresa - no sé si ésta es la palabra adecuada- de que en una lectura detallada (y malintencionada) el crítico llega a mencionar a un mayor número de poetas que de artistas visuales. No sólo eso sino que Greenberg además, a la altura de finales de la década de 1930 -como anteriormente Ortega y Gasset, hacia 1925, había hecho en La deshumanización del arte - deja entrever en el texto un primitivo y estrecho paralelismo entre arte y poesía, entre el arte por el arte -escribe- y la poesía pura. Se referirá, en varias ocasiones a lo largo del texto, al paralelismo entre "los procesos del arte y la literatura" (Greenberg 18). Las palabras empleadas, paralelismos y procesos, no son de ninguna manera un giro lingüístico neutral, sino todo lo contrario. Greenberg, como muchos otros críticos y teóricos del arte creía en la existencia de un paralelismo entre las artes, o mejor dicho, entre los procesos y evoluciones de la creación artística. Ahora bien, en ningún caso hablará de contagios o prestamos que hiciesen saltar por los aires las necesarias barreras entre disciplinas: procesos similares, soportes estrictamente diferentes e inintercambiables. Clement Greenberg lo ejemplifica en ese texto del siguiente modo:

Picasso, Braque, Mondrian, Miró, Kandinsky, Brancusi, y hasta Klee, Matisse y Cézanne tienen como fuente principal de inspiración el medio en que trabajan. El interés de su arte parece radicar ante todo en su preocupación pura por la invención y disposición de espacios, superficies, contornos, colores, etc., hasta llegar a la exclusión de todo lo que no esté necesariamente involucrado en esos factores. La atención de poetas como Rimbaud, Mallarmé, Valery, Éluard, Hart Crane, Stevens, e incluso Rilke y Yeats, parece centrarse en el esfuerzo por crear poesía (19). 
Si nos pusiéramos a jugar a teoría de conjuntos podríamos perfectamente hacer primero el conjunto de los pintores y luego el de los poetas, y luego ponernos a conectarlos, unos con otros, a través de flechas. Podemos llegar a preguntarnos: ¿quién va con quién? Es decir, había una afinidad, un paralelismo en los procesos. Aunque no es éste nuestro objetivo ahora, considero que es necesario señalar que para entender e interpretar la figura de Greenberg no se debería perder de vista este papel importante que juega la literatura para el crítico, en tanto que línea paralela de evolución (e incluso como guía de acción para la pintura). Baste de ejemplo, en este proceso de paralelismos entre arte y literatura, lo que afirma justo al final de "Pintura de tipo norteamericano", mediada la década de 1950: "Se sigue teniendo la impresión de que en este país [Estados Unidos] es tan difícil producir un arte de calidad como conseguir un buen vino. En literatura sí, sabemos que hemos hecho algunas cosas grandes; nos lo han dicho ingleses y franceses. Ahora pueden empezar a decirnos lo mismo de nuestra pintura" (256). Ansía, pues, un paralelismo entre las artes no sólo en lo referente al proceso de creación sino en igual medida en el proceso de recepción y de reconocimiento.

Greenberg, como es fácil deducir, otorga a literatura, y a la poesía en particular, un papel capital en todo el proceso de transformación de la vanguardia. En el año 1941 afirmará lo siguiente de la poesía de Bertold Brecht: "Sus instintos y hábitos como poeta imponen la forma, la medida, y la fuerza de penetración que se encuentran en casi todo lo que escribe. Su don es, sobre todo, el don del lenguaje" ("La poesía de Bertoltd Brecht” 295). Irá más lejos Greenberg, y así, partiendo genealógicamente de Mallarmé, sostendrá que la poesía fue una de las primeras disciplinas donde se alcanzó la abstracción y la pureza. Es decir, en la poesía, desde mediado el siglo XIX, con Mallarmé a la cabeza, se abre el camino hacia la posibilidad de esa abstracción, de esa aceptación del medio en el que se trabaja, en este caso, el lenguaje. Por lo tanto, las ideas que soportarán su concepción de la pintura, como es la aceptación del soporte, por ejemplo, serán igualmente aplicadas al poema. O dicho en otros términos, son los poetas antes que los pintores los que aceptan sin reparos el soporte en el que trabajan, y por lo tanto, en poetas como Mallarmé está ese origen clave de la modernidad. Por ello los poetas aparecen como elementos importantes para Greenberg. El poema es lenguaje, ése es su recinto, del mismo modo que la planitud es el recinto de la pintura. T. S. Eliot, unos años antes del texto de Greenberg, concretamente entre 1932 y 1933, había defendido algo similar. Escribía el poeta": "lo que el poeta experimenta no es la poesía, sino el material poético y lo que sentimos como lectores nunca es exactamente lo mismo que el poeta sintió" ("La mente moderna" 166), y en otro momento:

1 Este texto, de 1933, no es citado por Greenberg pero debió interesar al crítico. En él, Eliot propone una lectura de la mente moderna como un paso más en la experimentación de la creación y recepción del arte, y, por otro lado, le debió interesar en tanto que Eliot cita un texto de Trotsky, central para Greenberg en la preparación de su "Vanguardia y Kitsch", en el que afirma el carácter evolutivo del arte, su relación con la sociedad y con la política. Eliot traza una somera lectura de los paralelismos entre la literatura europea y la literatura soviética. 
"lo que se comunica es el poema mismo y sólo incidentalmente la experiencia y el pensamiento vertidos en él" ("Función de la poesía y función de la crítica" 59)². El esfuerzo, por lo tanto, se halla en el medio, es decir, en el lenguaje.

No es casual que haya traído a Eliot a este contexto. Son muchos los escritos de Greenberg sobre literatura, es cierto. No obstante, entre los escritores, como decía, serán los poetas su obsesión principal, y entre los poetas el que ocupará un lugar central será, precisamente, T.S. Eliot. Sí. Ese es el nombre por encima de Stevens, Pound o Williams. Ahora bien, la pregunta siguiente es importante: ¿Qué Eliot? O, mejor, ¿Qué de Eliot? Para Greenberg, la mirada sobre el poeta T.S. Eliot debe ser lo más amplia posible. Por ello no sólo le interesa el Eliot poeta -eso sería lo sencillo- sino la alianza o la interferencia que se establece en él entre el poeta y el crítico que fue Eliot. Recordemos que Greenberg, en el texto “T.S. Eliot: una reseña”, llega a decir lo siguiente: T.S. Eliot podría ser considerado el mejor de todos los críticos literarios" (265). A lo que añade, tajantemente:

una media docena de sus poemas me seguirá obsesionando como muy pocas cosas de las que he leído, teniendo en cuenta la época en la que empecé a leer poesía. Hay cosas en los versos de Eliot que nunca seré capaz de ver objetivamente porque pasaron a formar parte de mí hace demasiado tiempo (267).

Greenberg, por lo tanto, admite la imposibilidad de ver o de criticar objetivamente a Eliot, porque desde muy temprano, sus poemas lo llegaron a obsesionar. Ahora bien, si hablamos de poesía, ¿qué observa Greenberg en Eliot? ¿Qué le obsesiona de Eliot? Una lectura atenta del texto de Greenberg sobre el poeta delata al instante que lo que le interesa, o a lo que atiende con un mayor interés, es hacia aquellas obras del poeta donde la concepción misma de la obra se halla menos atenta al "argumento" o al contenido en un sentido documental del mismo y más pendiente del lenguaje, de la estructura $^{3}$. Es decir, le interesa, evidentemente, un trabajo como La tierra baldía, ante el cual señala que si bien las "diferentes partes no se mantienen unidas en el sentido de una composición en sí misma”, es precisamente esa desmembración de las partes, soportadas por el lenguaje como estructura celular básica, las que convierten a este poema en una gran obra de arte. En este sentido, Greenberg considera la literatura de Eliot en tanto que obra de arte, y eso, precisamente, representa para Greenberg buena parte de la producción de Eliot, al igual que la producción poética de Wallace Stevens, Hart Crane o William Carlos Williams, por seguir citando poetas estadounidenses. Pero avancemos con Eliot.

2 T. S. Eliot añade: "El poema tiene una existencia que está entre el poeta y el lector, una realidad que no es simplemente la realidad de lo que el escritor está tratando de expresar, o de su experiencia al escribir el poema, o de la experiencia del lector o del escritor como lector. Consecuentemente, el problema de lo que un poema 'significa' es mucho más difícil de lo que a primera vista parece” (Ibíd.).

3 Es más, eso es lo que le interesa también del Eliot crítico. Escribe: "si se prescinde del 'contenido' de su crítica, las virtudes del carácter o de la "forma" de la misma [...] resultan aún más notorias" (Ibíd.). 
Ante La tierra baldía (1922) -recordemos- nos situamos ante un libro que no está compuesto desde una conciencia creativa tradicional sino a través de un perfecto collage o pastiche donde los distintos fragmentos se entrelazan con el objetivo de arrastrarnos a través del lenguaje, al igual que ante una obra de arte nos dejamos arrastrar por el color o la pincelada. Y esto es lo que le interesa a Greenberg, no tanto el hecho de que sea un collage, sino por el hecho que sea un collage desde el propio material y medio que es el lenguaje. Un lenguaje que se convierte en el protagonista de la obra. Pero apunta algo más Greenberg. Considera además que en los mejores poemas de Eliot hay un añadido: música. Pero una música latente, que permanece escondida mientras leemos los poemas, que crea incluso el nexo de unión entre las palabras.

Un fragmento tomado al azar de La tierra baldía:
En la hora violeta, cuando los ojos y la espalda
se alzan del escritorio, cuando el motor humano
aguarda como un taxi palpitando a la espera,
yo, Tiresias, aunque ciego, palpitando entre dos vidas,
viejo, con arrugados pechos de mujer, veo
en la hora violeta, la hora de la tarde que conduce
al hogar y devuelve a casa al marinero,
la secretaria ya en casa a la hora del té, recoge el desayuno,
enciende la estufa y abre las conservas (Poesía selecta 79)

De la posterior obra del Eliot poeta tan sólo destacará un poema incluido en sus Cuatro cuartetos, el titulado "Burnt Norton", donde hallamos los siguientes versos: "Resuenan pisadas en la memoria / por la senda que no tomamos / hacia la puerta que jamás abrimos / ante el jardín de rosas. Así en tu mente / resuenan mis palabras" (141).

Ahora bien, esa obsesión por Eliot que él mismo reconoce, no se plasma en un desarrollo pleno. Así si en "Vanguardia y Kitsch" termina por insinuar un paralelismo en los procesos creadores entre poetas y pintores (estableciendo incluso un posible mapa de relaciones) esa misma idea -curiosamente- desaparece mediada la década de los cincuenta al hablar de T.S. Eliot. Es decir, no da las claves para un alineamiento entre la poesía de Eliot y la pintura, por ejemplo, de la época. ¿Cuáles serían entonces los paralelismos en los procesos creativos de Eliot? ¿Con qué pintor de esa década de los cincuenta o de pasadas décadas se podría establecer ese paralelismo? ¿Por qué Greenberg no dio ese paso? Quizá directamente porque la poesía de Eliot se deslizaba hacia caminos visuales que al propio Greenberg no le podían interesar. Para comentar esto, quizá, sea necesario que dejemos un momento a Greenberg aparcado.

Hacia finales de la década de 1960 Praz publica Mnemosyne. El paralelismo entre la literatura y las artes visuales. En esta obra desarrolla profusamente la idea que muy primitivamente -y con objetivos bien diferentes- había defendido Greenberg (quien no aparece mencionado en ningún momento) acerca de ese paralelismo a lo largo de la historia. Una evolución y una historia repleta de acontecimientos y vínculos directos. 
En cualquier caso la idea que mueve a Praz no es tan sólo -aunque también- referirse a "temas" o contenidos comunes entre ambas disciplinas, sino estudiar los procesos comunes. Afirmará tajantemente: "los temas no importan demasiado: lo que debe tenerse en cuenta es la manera en que están tratados" (21). Y acto seguido afina mucho más su argumento: "sólo cabe hablar de correspondencias cuando las intenciones expresivas y las poéticas son comparables y cuando hay similitud en los medios expresivos" (22-23). La tesis de Praz es clara: "El hecho de que un poeta pensara en determinado pintor al componer su poema no entraña necesariamente una similitud en cuanto a la poética y el estilo" (18). Es decir, el interés residirá en el modo en el que el poeta utiliza los medios expresivos del pintor y no, simplemente, sus temas. Lo que Praz rechaza (y suponemos que Greenberg en igual medida) son los simples paralelismos denominados "puramente temáticos" entre poesía y pintura, algo muy habitual en los estudios historiográficos sobre el tema, como es el caso del ya clásico libro de Helmt Hatzfield Literature through Art. A New Approach to French Literature [Literatura a través del arte]. Praz, con una profundidad y unas herramientas más sólidas que las de Clement Greenberg, se adentra a partir de esta idea en la evolución paralela de las artes. Y así, en el capítulo final del libro -tras haber analizado esos paralelismos desde la antigua Grecia- se ocupa en un breve texto final, precisamente, de eso que Greenberg tan sólo había dejado apuntado: el paralelismo entre la poesía de Eliot y el arte de su tiempo. En este caso Praz se referirá a la interpenetración de planos en la pintura, la escultura y la arquitectura y la interpenetración de palabras y significados en diversos escritores, entre los que hallamos a James Joyce y T.S. Eliot. En este sentido, no deja ser curiosa la afirmación siguiente: "La tierra baldía es un producto aún más heteróclito que 'Las señoritas de Aviñón”' (Praz 190). Praz considera que, a pesar de un posible paralelismo en la construcción de ambas obras, en las cuales hay un desmontaje parcial de los modos de composición convencionales, la poesía de Eliot es muchas más cosas diferentes al mismo tiempo -siendo una obra aún más arriesgada, opina Praz- en tanto que su material es estrictamente lingüístico. Y ese equilibrismo es el que le interesa, y es ese equilibrismo el que no llegó a definir -tal vez por falta de interés- Clement Greenberg.

Con La tierra baldía estamos ante una obra compuesta como un ensamblaje de diferentes elementos y citas literarias, coloquiales, científicas... que progresivamente van encontrando su espacio en el interior del poema. Y ahí estaba el enorme riesgo de Eliot, y ahí reside el interés que sobre su poesía despertó en poetas, artistas y críticos. De alguna manera el poema de Eliot es el soporte sobre el que las palabras se van distribuyendo hasta formar esta obra literaria que el propio Eliot entendía como objeto artístico, como artefacto artístico. Por lo tanto, ya en el inicio de la década de 1920, encontramos esa asociación caótica de citas implícitas o explícitas, con un fuerte sentido irónico, y, al mismo tiempo, jugando al equilibrismo, con un marcado sentido de la introspección. Hemos visto a Tiresias en una situación en la que comparte espacio con taxis, con latas de conserva y secretarias que llegan a su casa. Esta transposición 
(que podría recordar a algunas piezas de De Chirico) es lo que demuestra la radical importancia del poema de Eliot, donde profundidad y superficie se entrelazan. Toma, por ejemplo, expresiones coloquiales y las sitúa junto a expresiones del lenguaje culto. Es decir, mezcla tradiciones, alta y baja cultura, voltea expresiones sacando de contexto frases o versos clásicos y situándolos en escenarios paródicos, etc. Dicho de otro modo, crea un enorme pastiche donde la yuxtaposición de elementos y la superación del carácter argumental y lineal del lenguaje elevan el poema por encima de cada una de sus partes y le otorgan, a pesar de esta acumulación, una identidad propia. Por ello, Mario Praz, llegando donde Greenberg en su apasionado comentario de Eliot no alcanza, afirma ante La tierra baldía que "las mascaradas y cabriolas deliberadas entrañan el peligro constante de perder el equilibrio y caer desde el trapecio al vacío o directamente al serrín de la pista. Detrás de todas estas experiencias asoma la sospecha de que el artista se limita a "apuntalar con fragmentos sus ruinas", como dice Eliot en la conclusión de La tierra baldía” (Ibíd.). Podemos fijarnos en uno de los fragmentos/paisajes más sugerentes de La tierra baldía, fragmento que Praz sitúa en paralelo a las obras de Yves Tanguy y de Salvador Dalí, aunque quizá la atmósfera dechiriquiana hubiese sido -creo- lo más atinado. Ahora bien, más allá de eso, lo más importante es la estructura pastiche del poema (y no el simple paralelismo temático y visual) donde los elementos diferentes se yuxtaponen y se entrelazan:

$$
\begin{aligned}
& \text { Una rata se deslizó blandamente entre la vegetación } \\
& \text { arrastrando su viscosa panza por la orilla } \\
& \text { mientras yo pescaba en el turbio río } \\
& \text { una tarde de invierno, detrás de la fábrica de gas, } \\
& \text { musitando sobre el naufragio de mi hermano el rey } \\
& \text { y sobre la muerte previa del rey, mi padre. } \\
& \text { Cuerpos blancos desnudos sobre la baja tierra húmeda } \\
& \text { y huesos arrojados en un seco y bajo desván, } \\
& \text { entrechocados sólo por las ratas, año tras año. } \\
& \text { Pero a mi espalda de vez en cuando oigo } \\
& \text { el son de bocinas y motores que acercará } \\
& \text { a Sweeney a Mrs. Porter en primavera. } \\
& \text { Oh la luna brillaba clara sobre Mrs. Porter } \\
& \text { y sobre su hija (Eliot 77). }
\end{aligned}
$$

Y más adelante añade:

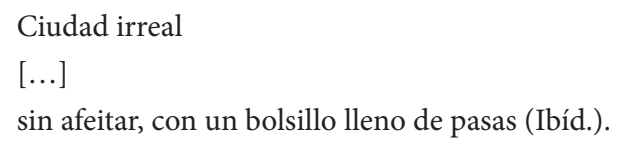

La composición de este fragmento es clara muestra de ese doble espacio sobre el que bascula el poema de Eliot: la creación de un paisaje desolado desde el lenguaje y, a su 
vez, un lenguaje que se sostiene sobre un conglomerado de frases e ideas ensambladas, procedentes de muy diversos espacios. Por ejemplo, en este fragmento hay versos de La tempestad de Shakespeare, de Marvell, de Verlaine y junto a ello, en el manual de instrucciones (que como Duchamp hará con ese otro gran proyecto de época que es el Gran vidrio) acompaña al libro, nos descubre que hay versos de los que desconoce el origen como "la balada de la cual he tomado estos versos: me llegó desde Sydney, Australia” (96). E, igualmente, la referencia final a las pasas proviene según él de lo siguiente: "Las pasas se cotizaban a un precio 'coste, seguro y transporte gratis a Londres', y el recibo, etc., era entregado al comprador al pago de la factura” (Ibíd.). Ésta es, precisamente, la recomposición que lleva a cabo Eliot. Una forma que se proyecta más allá de lo visual y que parte del lenguaje. Por eso le interesará a Greenberg, y por eso, sobre todo, les interesará a los poetas.

\section{El caso Frank O’Hara}

Ahora bien, demos un paso más y avancemos hacia nuestro objetivo, recogiendo a Greenberg donde le habíamos dejado: frente a T.S. Eliot. La referencia de Greenberg a Eliot, su importancia, su interés por el poeta -al que, es cierto, en ocasiones también critica y corrige- se da entre finales de los años cuarenta y a lo largo de los años cincuenta. Es decir, coincidiendo con todo el proceso de auge y desarrollo del expresionismo abstracto, espacio por el cual Greenberg es sobradamente conocido.

Planteémoslo entonces de otro modo y abramos así un segundo camino. Tanto Clement Greenberg como Mario Praz - lo hemos visto- cierran filas en torno a Eliot. El primero lo deja en el aire y el segundo profundiza en los paralelismos. Sin embargo, la pregunta ahora es, ¿qué sucede después? ¿cómo continúa la historia?

Resulta curioso el hecho sobre todo en la figura de Greenberg y el contexto más extenso de la escuela de Nueva York. Cuando en esos años centre su atención en lo que será el expresionismo abstracto, la poesía de ese tiempo desaparecerá sorprendentemente y por completo de su registro crítico. Si nos acercamos a un artículo sumamente importante y conocido como es "Pintura de tipo norteamericano", los poetas -en su mayoría curiosamente herederos de la poética de Eliot y Stevens- han desaparecido del mapa crítico. ¿Ya no hay poetas? Nos preguntamos. O mejor dicho, ¿ya no hay poetas con los cuales establecer paralelismos? Al contrario, el padrón de los poetas ha aumentado sustancialmente. ¿Por qué en el momento de referirse a la poesía en plena década de los cincuenta en lugar de mirar al presente como hace en el caso de la pintura mira hacia un poeta de los años 20? Evidentemente, no hay una respuesta clara. A lo más que podemos llegar es a afirmar o que bien la poesía del momento, coetánea del expresionismo abstracto e influida notablemente por él, no era su territorio y que aquello se le iba de manos (algo perfectamente comprensible) o bien cabe la posibilidad malintencionada (a la que me adhiero) de sospechar 
que esa poesía que se da en la también llamada Escuela de Nueva York, de la que evidentemente ha oído hablar y con la que está compartiendo espacio crítico, no le interesaba o no encajaba en su idea de lo que debía de ser la construcción del poema, donde el lenguaje era la materia prima exclusiva. ¿Cómo establecer paralelismos con estos poetas sino cabía esta posibilidad? Dicho de otro modo, en los poetas de la llamada Escuela de Nueva York donde se hallan Frank O'Hara, Kenneth Koch y John Ashbery, más jóvenes que sus mayores del expresionismo abstracto, existía un atisbo, aunque lejano, de contenido, por lo cual, esos poetas quedaban fuera de la férrea estructura teórica de Greenberg. Con los poetas anteriores podía llegar a ser sencillo y accesible pero no así, tal vez pensó, con los nuevos poetas. Eso en lo tocante a lo poético. Pero el asunto de la tirantez con los poetas no se cerraba ahí. Como veremos, la tirantez igualmente estribaba en la relación que poetas jóvenes como Robert Duncan, Robert Creeley, John Ashbery o Frank O'Hara tenían con el arte. Sobre todo estos dos últimos. El poeta John Ashbery era crítico de arte en la revista Art News en la segunda mitad de la década de los cincuenta. Por su parte, Frank O'Hara, no sólo era crítico de arte en Art News sino que también acabaría escribiendo una monografía a finales de los cincuenta acerca de nada más y nada menos que Jackson Pollock ${ }^{4}$, siendo, entre 1960 y 1966 (cuando murió con cuarenta años), conservador de pintura y escultura en el Museo de Arte Moderno de Nueva York. En resumen, que con estos datos superficiales, nos hacemos una idea de que Greenberg, aún conociendo el trabajo de estos poetas muy cercanos, situados en paralelo, como diría Praz, a los pintores de la escuela de Nueva York, no asoman la cabeza en ninguno de sus textos, en tanto que poetas.

Analicémoslo más de cerca. Como es sabido, a partir de la década de los cuarenta - coincidiendo aproximadamente con el fin de la II Guerra Mundial- la poesía comienza a diluirse del panorama artístico europeo, comienza a difuminarse, a desdibujarse, transformándose en una género anacrónico. Así, lo poético acabará por ceder su espacio y su altar místico - como centro espiritual- a la pintura. Como consecuencia la alta poesía europea cede su trono a la gran poesía norteamericana del siglo XX, con Wallace Stevens o William Carlos Williams como cabezas visibles de una nueva genealogía. Así mismo, en las generaciones siguientes algunos poetas dejan de tener como referencia a Cézanne $e^{5}$ y pasan a ver en Pollock y en De Kooning a los pintores que mejor reflejan su presente, tanto hacia dentro - es decir, emocionalmente-como hacia fuera -es decir, social y circunstancialmente-. Con ello, pintura y poesía adquieren una nueva conexión. Una conexión que no se va a reducir a lo temático, a un

4 Jackson Pollock (1959). Otros textos sobre arte y exposiciones los hallamos reunidos en los siguiente libros: New Spanish painting and sculpture (1960); Robert Motherwell: with selections from the artist's writings (1965); Nakian (1966); Art Chronicles, 1954-1966 (1975).

5 Sobre la obsesión que a lo largo del siglo XX han tenido los escritores y filósofos sobre la figura de Cézanne, léase el interesante capítulo "Como Cézanne en pintura", del libro de Domingo Hernández Sánchez, La ironía estética. Estética romántica y arte moderno (2002). 
simple imaginario común, sino que junto a esto hallaremos la apropiación de técnicas pictóricas en el interior del poema.

Por lo tanto en esta segunda parte me voy a centrar en la relación de la poesía de alguno de esos poetas de la escuela de Nueva York. Fundamentalmente me centraré en el caso paradigmático de Frank O'Hara. La relación que este poeta entabla con la pintura, con los pintores y con los procesos de construcción del poema y de la pintura, son el ejemplo claro de ese paralelismo, de esa interpenetración entre disciplinas que le interesaba a Mario Praz. En cualquier caso, para tratar estas cuestiones y para poder, aunque sea rápidamente, profundizar en este hecho, me he de referir primero a otro poeta, fundamental en este proceso. Me refiero al poeta Charles Olson. Olson fue rector de la Black Mountain College entre 1952 y 1956, es decir, años centrales en la historia del arte contemporáneo. Como es sabido, Black Mountain College fue una universidad experiemental, tal y como suele definirse, situada en Carolina del Norte, y allí, en un corto espacio de tiempo, hallamos como estudiantes o como profesores a artistas como Kline, Rauschenberg, Cage, Tudor, Cunningham, Kenneth Noland o Robert Creeley. De sobra es conocido el hecho de que fue allí donde tuvo lugar el primer happening y que cuando Cage, Tudor y Cunningham entraron a formar parte de la universidad se hizo posible el nacimiento de la Compañía de danza moderna. Por lo tanto, un poeta como Olson estaba muy pendiente de los diferentes movimientos artísticos que entonces se ejecutaban y de alguna manera trató de establecer caminos de conexión entre las diversas disciplinas. Este hecho, o esta intención, derivó en la construcción teórica de lo que se llamará verso proyectivo, un tipo de construcción poética -en el sentido etimológico y más amplio del término- que veremos en varios artistas, no sólo en los poetas. Si leemos algunas de sus ideas sobre la creación, podemos ver representada esa década de los cincuenta, tanto para la poesía como para el arte en general. Escribe Olson:

El poema mismo tiene que, en todo momento, ser una construcción de alta energía y, en todo momento, una descarga de energía [...] Con la cinética sólo se puede hacer una cosa, volver a repetirla. Que es por lo que un señor dijo que el que posee el ritmo posee el universo, y por lo que el arte es lo único gemelo a la vida, su única metafísica válida. El arte no pretende describir, sino actuar y si el hombre tiene que alcanzar de nuevo un propósito en su vida, tiene que comprender del todo su propio proceso, desde fuera; a través de su propia piel, hacia dentro; y por sus propios poderes de conversión hacia afuera de nuevo [...] La forma no es más que una extensión del contenido. El hecho es que no puede existir la forma como posibilidad independiente de aquello que la anima, de cuyo contenido es resultado [...] Lenguaje como acto del instante... [no] como acto del pensamiento sobre el instante (Projective verse párr. 1$)^{6}$. 
Todas estas ideas de Charles Olson quedan resumidas en el momento en que afirma: "La abstracción expresa el modo de interacción de la naturaleza y no es meramente mental. Cuando el pensamiento abstrae, sólo está sometiéndose a la naturaleza, o, mejor dicho, está manifestando un componente de la naturaleza" (Ibíd.) ${ }^{7}$. Para Olson, como para el resto de poetas, así como para los pintores sobre los que Greenberg trabaja, la abstracción aparece como el ritmo donde efectivamente -según palabras de Olson- se asume y se devuelve la energía que existe en nosotros y a nuestro alrededor. Este espacio proyectivo, en palabras de Olson, es el que comparten tanto los artistas visuales como los poetas del momento.

Por otra parte, junto a lo teórico es necesario destacar lo personal. No es posible obviar la estrecha relación que los poetas y pintores de ese momento mantenían entre sí. Es decir, existía una transfusión diaria de ideas y conocimientos. Mencionado en muy diversos lugares es, por ejemplo, el momento en el que Jackson Pollock y el poeta Robert Creeley se conocieron. Kevin Power lo describe perfectamente:

Según parece se encontraron en un bar de Greenwich Village sin conocerse previamente. Lo que le preocupaba a cada uno en aquel instante era delimitar contra posibles injerencias la parte de la barra que les correspondía. La escena, que se prestaba a la clásica pelea de bar con botellazos en la cabeza, concluyó cuando Creeley oyó que alguien se dirigía al desconocido por el nombre de Pollock. A partir de ese momento el panorama cambió radicalmente, terminando los dos por saludarse y mostrarse fotos de sus respectivas familias (114-15).

Volvamos a O'Hara. Como Eliot, Frank O'Hara era crítico y poeta. Ahora bien, era crítico de arte. No deja de ser curiosa la larga lista de poetas que a la par ejercen de críticos de arte en Estados Unidos ${ }^{8}$. En cualquier caso, es necesario señalarlo, Frank O'Hara fue un enorme poeta. Antes hemos dado alguna pista biográfica de O'Hara, seguidor a su vez de T.S. Eliot. Hemos comentado que O'Hara no sólo era poeta, sino que además conocía los entresijos del arte ${ }^{9}$ en Nueva York desde comienzos de la década de los cincuenta, en tanto que crítico de arte, amigo de Pollock, de De Kooning, de Jasper Johns o de Larry Rivers, por ejemplo. Ahora bien, al enfrentarlo a Greenberg he ocultado una carta. Una carta importante, y que está detrás de la distancia central con Greenberg, y por la cual, tal vez, no vería con buenos ojos a estos poetas. Si Greenberg en el año 1955 publica su "Pintura de tipo norteamericano" donde comienza a atisbar una deriva figurativa peligrosa, según su idea de lo que era la pintura, y regaña ${ }^{10}$ a determinados pintores por salirse del camino de la

\footnotetext{
7 Traducción del autor.

8 Entre los más recientes encontramos a Michael Fried, Donald Kuspit, Robert C. Morgan, etc.

9 Cf. Marjorie Perloff: Frank O'Hara: Poet among Painters. (1997).

10 Al referirse a De Kooning en ese texto afirmará: "De Kooning se muestra tan impotente como Picasso para arrancarse de la figura y de ese modelado para el que tan bien le equiparon su sentido del contorno y del claroscuro. Y hay quizás un orgullo aún más luciferino detrás de la ambición de De Kooning que de la de Picasso; si hubiese
} 
vanguardia y de la abstracción, no debemos perder de vista que Frank O'Hara había publicado el año anterior su "Naturaleza y nueva pintura" donde defendía, a través de pintores como Elaine De Kooning, Larry Rivers o Grace Hartigan, la posibilidad de un expresionismo figurativo dentro del expresionismo abstracto. Era evidente, pues, que algo estaba sucediendo, y la respuesta de Greenberg a toda esa deriva epocal fue "Pintura de tipo norteamericano". No olvidemos, además, que en la única referencia que hallamos en O'Hara dedicada a Greenberg en sus obras completas este aparece definido con la contenida e irónica descripción de "órfico".

Dejando de lado la vertiente de crítico de O'Hara -quizá la más conocida en nuestro terreno universitario- me gustaría centrarme en el $\mathrm{O}^{\prime}$ Hara poeta y su conexión con la pintura de su época. Cuando en la década de los cincuenta junto a John Ashbery y Kenneth Koch, entre otros, crean la Escuela de Nueva York lo hacen con la intención de fundir y conectar teatro, poesía, pintura y música. Es decir, abrir un espacio intelectual en el que los artistas buscasen una temática y lenguaje comunes. Es más, buena parte de su poesía se publicó en colaboración con artistas plásticos como Larry Rivers y Michael Goldberg. Por lo tanto se mantenía una vía fluida de conexión entre artistas; entre poetas y pintores, fundamentalmente.

En cualquier caso es necesario entender la poética de O 'Hara, una poética (y una crítica) que se vio truncada por su trágica muerte en un accidente en $1966^{11}$. Siguiendo la estela de las nuevas poéticas en el mundo del arte, O'Hara considerará el poema como un espacio donde todo es posible, pero tomado, principalmente, como el encuentro entre dos personas. De este modo lo definió en su manifiesto titulado "Personismo". Y así, si bien no se trataba de una poesía documental o realista, sí que trataba, a través del collage y del pastiche de conversaciones escuchadas aquí y allá, de crear una atmósfera abstracta y figurativa al mismo tiempo -si eso era posible- donde el lector se mantuviese alerta en busca del contenido siempre presente y oculto, es decir, como afirmará él mismo O'Hara: “como en un cuadro de De Kooning" (Cit. en Power 345). En las obras de pintores como De Kooning, como en los versos de Frank O’Hara, el acto de la comunicación y el resultado final de la composición son una y la misma cosa, ya que en última instancia lo que importa es la crónica del acto de la creación. Ante sus poemas, como ante los de John Ashbery, parece siempre que estemos a punto de hallar la clave del poema, su significado, pero al instante hemos de rendirnos ante la imposibilidad de encontrar ese sentido, dado que al final lo que importa es el proceso mismo de la escritura. Cabe, en cualquier caso, antes de analizar algunos de los poemas de O'Hara sobre pintura, destacar la importancia que tanto ésta como la convivencia con los pintores tuvo para su actividad poética.

hecho realidad todas sus metas, cualquier otra pintura con ambiciones habría tenido su curso durante toda una generación, pues él habría marcado sus límites por delante y por detrás" (256).

11 Frank O’Hara murió en 1964, arrollado por un vehículo en la playa de Fire Island, Long Island, Nueva York. 
O'Hara era un poeta que recogía de la ciudad todo el material para su poesía. Por ejemplo, los poemas incluidos en Poemas del almuerzo fueron escritos durante las ajetreadas horas de almuerzo en las calles de Nueva York. Por ello resulta evidente que no podemos obviar la siguiente historia que, al hablar del clima cultural que se vivía en Nueva York, se transforma en una definición de su propia actividad creativa:

Todos teníamos alrededor de veinte años. John Ashbery, Barbara Guest, Kenneth Koch y yo, al ser poetas, repartíamos nuestro tiempo entre el bar literario, el San Remo, y el bar de los artistas, la taberna Cedar. En el San Remo discutíamos y chismorreábamos; en Cedar a menudo escribíamos poemas escuchando discutir y chismorrear a los pintores... Un detalle interesante de estas actividades sociales era que, siendo nosotros poetas no académicos y, por supuesto, no literarios, en el escenario americano del momento los pintores eran nuestra única y generosa audiencia, la mayoría de nosotros leíamos públicamente por primera vez en galerías de arte. Al establishment literario le importaba nuestra poesía lo mismo que a la colección Frick le importaban Pollock o De Kooning (Cit. en Power 333).

Este simple documento biográfico deja bien a las claras la presencia significativa que para los poetas del momento tuvieron determinados pintores, no sólo como guías que marcan el camino sino también, en igual medida, como audiencia de su propia obra. Algo, que en el caso de O'Hara, deja bien claro John Ashbery en la introducción a sus obras completas: "El concepto del poema como crónica del acto creativo de O'Hara se fortaleció gracias a su íntima experiencia de los inmensos cuadros de Pollock y De Kooning de fines de los 40 y principios de los 50, y del realismo imaginativo de pintores como Larry Rivers" (Ibíd.).

Curiosamente, y sin salirnos del binomio newyorkino Ashbery-O'Hara, encontramos otro de esos momentos capitales en la interrelación de las artes, en este caso la música. Cuenta Ashbery que mientras sufría hacia 1950 una profunda crisis creativa O'Hara lo llevó a un concierto. Así lo narra Ashbery:

Todo comenzó a cambiar cuando salí con Frank O'Hara a un concierto de David Tudor que interpretaba "Music of Changes" de John Cage el día de año nuevo de 1952. La obra constaba de una serie de acordes disonantes, la mayoría altos y de ritmos irregulares. Duró más de una hora y se me antojaba que podía continuar indefinidamente. Tras escucharlo me sentí profundamente renovado, y comencé a escribir de nuevo poco después. Sentí que podía ser tan especial en mi poesía como lo era Cage en la música (Cit. en Power 332).

“Como lo era Cage en la música”, sería otro modo de interpretar la poesía de estos poetas ${ }^{12}$.

12 El mismo Ashbery sostendrá: "Lo que me gusta de la música es su capacidad para resultar convincente, para llevar un argumento satisfactoriamente hasta la conclusión, aunque los términos del argumento sigan siendo cantidades desconocidas. Lo que queda es la estructura, la arquitectura del argumento, la escena o la historia. Me gustaría hacer esto en poesía" (Cit. en Power 332). 
En cualquier caso, la poesía de O'Hara tiene una enorme capacidad inclusiva. Pero esa inclusión no implica, como decía, una descripción realista de los hechos. Le interesa incluir en el poema las experiencias caóticas que lo rodean. Escribe:

Lo que me interesa del mundo es, sobre todo, el modo en que yo lo experimento, y a veces, cuando preferiría estar muerto, el pensar que nunca más podría escribir otro poema me ha impedido suicidarme. Lo que me va pasando incluyendo las mentiras y las exageraciones que trato de evitar, lo pongo en mis poemas. No creo que mis experiencias se hagan más claras o más bellas, ni para mí, ni para nadie... (Cit. en Power 333).

Y en este sentido la presencia de la pintura de De Kooning se le torna revelación capital. Esto es, el modo en el que el sujeto lírico experimenta su realidad, sus espacios más próximos. Pongamos un ejemplo. La Segunda avenida, en Nueva York, era su territorio propicio, su hábitat, incluso su zona de trabajo para la creación, algo así como su estudio. Basta recordar, a modo de inciso, las palabras del pintor Joe Brainard, incluidas en su fascinante libro Me acuerdo:

Recuerdo la primera vez que vi a Frank O’Hara. El iba caminando por la Segunda Avenida. Era una tarde fresca de principios de primavera, pero él llevaba sólo una camisa blanca arremangada hasta los codos. Y vaqueros. Y mocasines. Recuerdo que me pareció muy mariquita. Muy teatral. Decadente. Recuerdo que me gustó al instante.

Recuerdo aprender a jugar al bridge para poder conocer mejor a Frank O'Hara. Recuerdo jugar al bridge con Frank O’Hara. (Sobre todo, hablábamos).

Recuerdo los andares de Frank O'Hara. Ligeros y mariquitas. Con un suave contoneo y una sutil contorsión. Eran unos andares hermosos. Confiados. "No me importa" y a veces "Sé que estás mirando".

Recuerdo el día que Frank O’Hara murió. Intenté pintar, de alguna manera, algo especialmente para él. El resultado fue horroroso (84).

En cualquier caso, la colaboración entre ambos fue estrecha durante los primeros años de la década de 1960.

La Segunda Avenida que mencionaba Brainard al referirse a O'Hara es en sí misma un poema por desarrollar, una caótica obra de arte compuesta por el flujo de la vida, por el ir y venir de la gente, por las conversaciones cruzándose, por los gestos perdidos, por las miradas sin destino fijo, etc. Todo esto es lo que pretende rescatar en un poema como "Second Avenue" donde nos topamos con uno de los textos/ tejidos más complejos de O'Hara, pero en igual medida con uno de sus mejores y más sugerentes poemas. El ambiente urbano insinuado se nos ofrece en este extenso poema de 1960 (publicado junto a obra de Larry Rivers), no escribiendo directa o figurativamente sobre Nueva York, sino sobre "lo que le ocurrió, o sintió que le había ocurrido”. O’Hara, en este poema, y en general en su concepción de la poesía, defiende 
la creación de un poema discontinuo que hace material poético de cualquier artefacto, persona, idea, o lugar. Pero esta operación que surge del enfrentamiento con el caos urbano provoca una energía -recordemos a Charles Olson- poética que se apoya en un nuevo tipo de relación ilógica entre el hombre y su realidad circundante: "Mis manos son Massimo Plaster, llamado 'Alfiler Blanco en el Brazo del Mar' / Y yo estoy encendido y abrasado como campanillas al viento en Pulasky Skyway / repisas de Viena llevan bultos de celofán a la lavandería" (O’Hara 139).

En este poema De Kooning aparecerá tanto implícita como explícitamente. Se nos presenta como personaje, pero en igual medida aparece como inspirador del mismo. En sus "Notas sobre Second Avenue" escribirá, precisamente que la obra de De Kooning, su forma de enfrentarse a la ciudad no como objeto cerrado y definido, sino como una acumulación de incoherencias anónimas y fragmentos, es lo que está detrás de este gran poema. Y cita, como directa influencia, tres obras de De Kooning: "Ashville", "Excavation", "Gansevoorts Street".

Esta es la poética desbordante de $\mathrm{O}^{\prime} \mathrm{Hara}$ que hallamos en sus mejores poemas y que, como él mismo reconocerá, proviene en la mayor parte de los casos de la obra de pintores como Willem De Kooning. El propio poeta reconoció la importancia capital en la redefinición de su vocabulario artístico que tuvo De Kooning, que según afirma, le enseñó un nuevo modo de experimentar lo real. Así, hallamos en su obra, en constante conflicto irresoluble, contradicciones, ambigüedades, afirmaciones y negaciones en un invariable proceso de acumulación lingüística. Lo cotidiano y lo percibido por los sentidos, con sus múltiples tonos y perspectivas, confiere un valor poético a un presente experimentado como momentos desconectados y luego reconectados por la aparición de detalles (objetos, transeúntes, etc.). El hablante lírico va captando en estos versos el dinamismo de la ciudad, poetizando lo trivial y despojándolo del sentido de causalidad. Por ello la fragmentación, el azar, la ausencia de control fueron centrales en su forma de experimentar el acto poético y su experiencia de la ciudad. Evidentemente, todo ello le llevó a la composición de su conocido poema "Oda a Willem De Kooning", escrito hacia 1950:

Más allá del amanecer / donde empieza la negrura / una ciudad enorme / va subiendo las persianas / y justo antes del último lapso de valor, del que ya me arrepiento, que / los amigos describen como «esta vez tan solo» en un / infierno temporal, espero / tratar de apoderarme de la grandeza / que me es disponible / por la generosidad Y / el derroche del espíritu, lo tuyo / no ser un pintoresco / inimitable débil yo mismo / pero estar de pie claramente / solo en el viento anaranjado / mientras ruedan y gritan a través de Gotham y Los / estrechos de Pascua / y no tengo el valor para condenarme por mi cobardía / [...] Y salir al mundo / hipnotizados / de voces íntimas como ruidos / de tráfico, abriendo un claro / en el atestado abismo de occidente (283). 
Éste es sólo un breve fragmento del poema donde el poeta ha pretendido no sólo tematizar un hecho o una experiencia que sufre ante un cuadro sino, en mayor medida, situarse en el cuadro. Es decir, ha pretendido ser la experiencia azarosa del pintor e incluso tratar de emplear sus propias técnicas.

La personalidad de De Kooning -como puede observarse fácilmente- es fundamental en O'Hara. En otro poema titulado "Radio", unos años más tarde, escribe hacia el final: "Bien, tengo mi hermoso de Kooning / al cual aspirar. Pienso que tiene una cama / naranja en él, es más de lo que el oído puede sostener” (97). De Kooning es siempre una aspiración para él. Este poema incluye una curiosidad. El 22 de marzo de 1956, Kenneth Koch le envía una carta a O'Hara en la que le cuenta que la noche anterior estuvo bebiendo con De Kooning y le había preguntado si había leído los poemas de O 'Hara. Dijo que sí, que le habían gustado. Entonces Koch recordó los últimos versos de "Radio". Fue entonces cuando De Kooning le dijo que le gustaban los versos pero que en el cuadro no había ninguna cama sino un sofá. A pesar de ello De Kooning sostuvo que le gustaba más la imagen de la cama. La consideró un acierto y que encajaba con su idea de la obra. Y añadió que le gustaba la imagen de la cama ya que los colchones tienen una movilidad, unas mutaciones muy parecidas a las de la Tierra y que por ello le interesaba el cambio de imagen que provocaba el poema de O'Hara.

Utilizando igualmente palabras de Pollock afirmará que a través de la acumulación y el movimiento trata de "explorar las posibilidades del descubrimiento" (112). Precisamente, al igual que De Kooning, Pollock es objeto de poema. Escribe el poema titulado "Digresión sobre Número 1, 1948":

Estoy enfermo, aunque no estoy

demasiado enfermo. No estoy enfermo en absoluto.

Es un día perfecto, demasiado caluroso

para el invierno, demasiado frío para el otoño.

Un buen día para contemplar. Observo,

durante la hora del almuerzo, una cerámica

de Miró, y luego veo el mar de Léger;

la luz de un complejo Metzinger

y el rudo despertar de Brauner,

una mesita de Picasso, de color rosa.

Estoy cansado, pero no estoy

demasiado cansado. No estoy cansado en absoluto.

Ahí está el Pollock, blanco, el daño

derramado, su mano perfecta

y sus muchos viajes de un lado a otro (260). 
Es evidente, en definitiva, y queda bien a las claras, la profunda huella que los pintores del expresionismo abstracto (una especie de hermanos mayores) dejaron en los poetas. Aunque, de un modo capital, fue De Kooning la figura titular e inspiradora. Y entre las cosas que mayor interés desatan en el $\mathrm{O}^{\prime}$ Hara poeta es el concepto de no-entorno que desarrolla el pintor y que el poeta pretende dirigir hacia la creación poética. La idea del no-entorno subraya el anonimato esencial de la ciudad. Existe en su obra un creciente interés por el anonimato de los suburbios, por la arquitectura anónima de la ciudad. El no-entorno se impone como una especie de autobiografía de la ciudad; una autobiografía que se sabe de antemano fallida, porque será incapaz de cerrarse, de concluirse. El yo se convierte en algo fugaz y establece relaciones caóticas con su entorno. Del mismo modo que la vida carece de una linealidad argumental, de la misma forma que la existencia -afirma - tiene un carácter amorfo y no definido, así debe ser el acto creativo. Por ello, un crítico como Kevin Power observa que "O'Hara y De Kooning aceptan la visión felliniana de la vida como circo, como desfile de incidentes, de fragmentos, un remolino de memoria y sucesos dentro de la masa de la masa de memoria y sucesos" (237). Evidentemente estos poetas, con O'Hara a la cabeza, tienen en mente y como referencia clara la conocida serie de la Mujeres. Esa mezcla caótica de organicidad y sexualidad expresionista, esas azarosas formas sin sentido que acaba conformando el caótico cuerpo de una mujer suponen para O 'Hara, y el resto de poetas, el reflejo de lo que ellos tratan de reflejar en su escritura. Por ello insiten su "como en un cuadro de De Kooning". Precisamente en el citado "Second Avenue", O'Hara describe -el mismo lo reconoce- la presencia de esas mujeres:

$$
\begin{aligned}
& \text { Seguiste siendo para mí un Buick verde de suspiros, joh, Gladstone! } \\
& \text { y Trina, tú, mujer, cuán semejante a una almohada amarilla en el alféizar, } \\
& \text { en el creúsculo colmado de ventanas donde está compartimentando el aire } \\
& \text { sus labios rojos de Hollywood, suaves como el Tiziano y tan tiernos, } \\
& \text { su cara gris que se abstiene de echar a un lado la melena } \\
& \text { de tus negros y lánguidos olores, la mano aplastada bajo el mentón } \\
& \text { y ese territorio de letargos, de oscuras líneas cutáneas que se tambalean } \\
& \text { bajo el peso de su oscura y multicolor corpulencia de arbustos, de } \\
& \text { ropa de sábana y satén, como una rosa solitaria con el cielo detrás (128). }
\end{aligned}
$$

Para concluir me gustaría centrarme en un último poema de O'Hara que si bien no trata directamente de De Kooning, muestra sus relaciones directas con la herencia de éste y con la pintura de la época. Me refiero al que es, para mí, quizá el mejor poema de O'Hara: “¿Por qué no soy pintor?”

No soy pintor, soy poeta.

¿Por qué? Creo que preferiría ser

pintor, pero no lo soy. Bueno,

por ejemplo, Mike Goldberg

está empezando un cuadro. Me paso a verlo. 


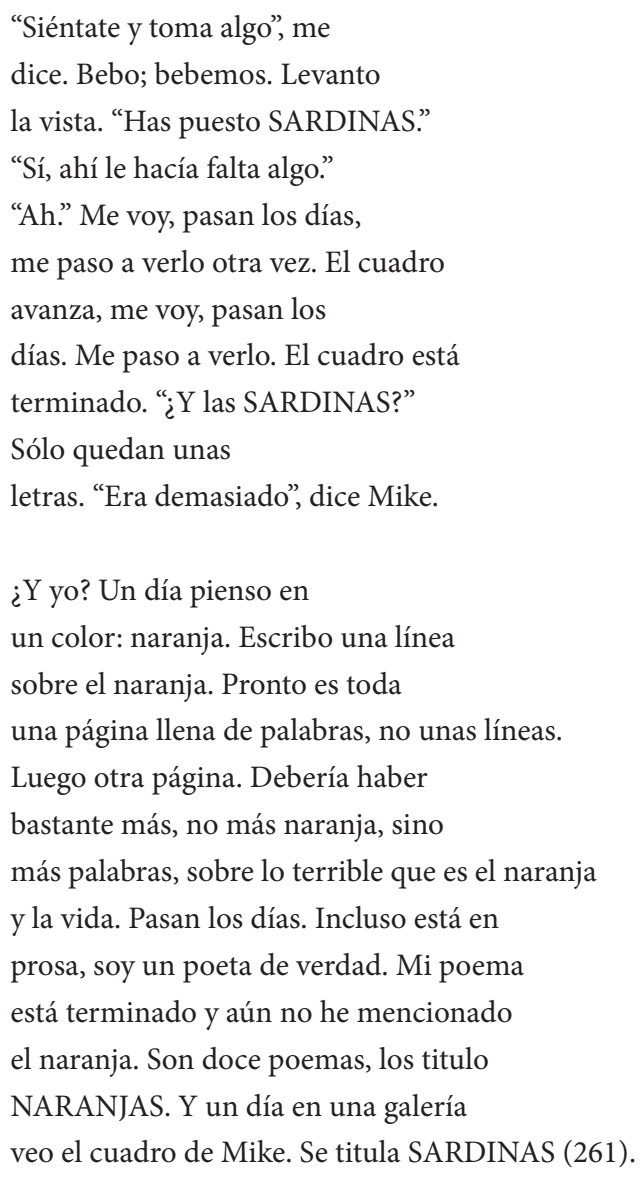

Este poema refleja la tensión compositiva desde el mismo paródico título. En realidad el ser o no ser pintor es lo mismo, lo que late detrás es el hecho de un paralelismo en el proceso de composición. Lo que está llevando a cabo es la comparación compositiva de su libro Naranjas: 12 pastorales, de 1953 y el cuadro "Sardinas" de Michael Goldberg, de 1955. El poema apareció en la revista Evergreen Review en el año 1957. En la primera sección del poema el poeta es simplemente el observador del proceso de composición del pintor, para, en la segunda sección del poema, transformarse en el protagonista. Este poema, es, creo, el perfecto resumen de ese vínculo, no demasiado explorado, y del que este trabajo pretende ser una mínima muestra de la interrelación existente, sobre todo en la poesía norteamericana entre arte y poesía, entre los procesos del arte y la poesía. Una tradición que aún hoy sigue abierta. 


\section{Referencias}

Brainard, Joe. Me acuerdo. Trad. Julia Osuna Aguilar. Madrid: Sexto Piso, 2009. Medio impreso.

Eliot, Thomas Stearns. "La mente moderna”. Función de la poesía y función de la crítica. Trad. Jaime Gil de Biedma. Barcelona: Tusquets,1999. Medio impreso.

---. Poesía selecta (1909-1942). Trad. Juan Malpartida y Jordi Doce. Barcelona: Círculo de Lectores, 2001. Medio impreso.

Greenberg, Clement. "La poesía de Bertold Brecht”. Arte y cultura. Ensayos críticos. Trad. Justo G. Beramendi. Barcelona: Paidós Estética, 2002. 295-302. Medio impreso.

---. "Pintura de tipo norteamericano". Arte y cultura. Ensayos críticos. Trad. Justo G. Beramendi. Barcelona: Paidós Estética, 2002. 256-293 .Medio impreso.

---. “T.S. Eliot: una reseña”. Arte y cultura. Ensayos críticos. Trad. Justo G. Beramendi. Barcelona: Paidós Estética, 2002. 33-44. Medio impreso.

---. "Vanguardia y Kitsch". Arte y cultura. Ensayos críticos. Trad. Justo G. Beramendi. Barcelona: Paidós Estética, 2002. 15-34. Medio impreso.

Hatzfield, Helmt: Literature through Art. A New Approach to French Literature. New York: Oxford University Press, 1952. Medio impreso.

O'Hara, Frank. Jackson Pollock. New York: George Braziller, 1959. Medio impreso.

---. Nature and new painting. New York: Tiber Press,1954. Medio impreso.

---. The Collected Poems. Ciudad: California University Press, 1995. Medio impreso.

Power, Kevin. Una poética activa. Poesía estadounidense del siglo XX. Trad. Alvaro Carrasco, Carmen García del Potro, Francisco Godoy, Jorge Guitart, Mario Hernández, Pablo Gianera. Santiago: Universidad Diego Portales, 2009. Medio impreso.

Praz, Mario. Mnemosyne. El paralelismo entre la literatura y las artes visuales. Trad. Ricardo Pochtar. Taurus, Madrid, 2007. Medio impreso.

Recibido: 28 septiembre 2013

Aceptado: 14 septiembre 2014 